QUADERNS DE FILOSOFIA VOL. VI NÚM. I (20I9): 59-76

eISSN: 234I-3042 DOI: IO.7203/QFIA. 6.I.I 4825

JaVIER SuÁreZ \& VANESSA TRIVIÑO*

LOGOS, Universitat de Barcelona-Universidad Rey Juan Carlos I de Madrid

\title{
A metaphysical approach to holobiont individuality: Holobionts as emergent individuals
}

Received: 6-7-2017 / Accepted: 14-3-2019

\begin{abstract}
Holobionts are symbiotic assemblages composed by a host plus its microbiome. The status of holobionts as individuals has recently been a subject of continuous controversy, which has given rise to two main positions: on the one hand, holobiont advocates argue that holobionts are biological individuals; on the other, holobiont detractors argue that they are just mere chimeras or ecological communities, but not individuals. Both parties in the dispute develop their arguments from the framework of the philosophy of biology, in terms of what it takes for a "conglomerate" to be considered an interesting individual from a biological point of view. However, the debates about holobiont individuality have important ontological implications that have remained vaguely explored from a metaphysical framework. The purpose of this paper is to cover that gap by presenting a metaphysical approach to holobionts individuality. Drawing upon a conception of natural selection that puts the focus on the transgenerational recurrence of the traits and that supports the thesis that holobionts are units of selection, we argue that holobionts bear emergent traits and exert downward powers over the entities that compose them. In this vein, we argue, a reasonable argument can be made for conceiving holobionts as emergent biological individuals.
\end{abstract}

Keywords: emergence, holobiont, symbiosis, microbiome, biological individuality, trait-recurrence.

\footnotetext{
*E-mails: javier.suarez@ub.edu, vanesa.trivino@urjc.es
} 

not walk alone either: they are given in a vast ocean of microbes that find, in different parts of their body surfaces, a comfortable site where they can grow and reproduce. Furthermore, macroorganisms need some of their microorganisms to properly develop and to adequately realize some of their basic functions, including physiological processes like metabolism or immunological defense (Dethlefsen et al. 2007; Gilbert et al. 20 i2; Brucker \& Bordenstein 20I3; McFall-Ngai et al. 20 i3; Hill et al. 20 i6; Chiu \& Eberl 20i6). The observation of these facts has led some biologists to formulate the so-called holobiont thesis. According to this thesis, there is a new level of biological individuality that would encompass the entity formed as a consequence of the association of the macrobe host with all the symbiotic microorganisms that constitute its microbiome, including Archaea, bacteria, fungi, and viruses. ${ }^{2}$ This new level of individuality is called "holobiont", and the sum of all the genetic information in a holobiont is called "hologenome" (Rosenberg et al. 2007; see SuÁrez 20 I 8, for a review of the evolution of the holobiont concept).

Most of the recent debates about holobionts are oriented to either justify or reject their status as biological individuals. On the one hand, advocates of the holobiont thesis argue that the high level of interdependence that exists between macrobes and their symbiotic microorganisms calls for a redefinition of biological individuality. Under the new redefinition, holobionts would be biological individuals in an anatomical, immunological, developmental, physiological, and even in an evolutionary form, constituting a unit of selection in evolution (ZILBERRosenberg \& Rosenberg 2008; Dupré \& O’Malley 2009; Gilbert et al. 20 i 2; 20I7; Rosenberg \& Zilber-Rosenberg 20 i4; 20i6; Díaz 20 I 5; Bordenstein \& Theis 20i6; Theis et al. 20 i6; Lloyd 20I7b; Roughgarden et al. 20 i 8). ${ }^{3}$

${ }^{1}$ Throughout the paper, we will refer to animals and plants as "macrobes"/"macroorganisms", following a famous notation introduced by O'Malley \& Dupré (2007). Furthermore, when we refer to the "macrobe host", we mean the monogenomic individual that derives from a zygote (DUPRÉ 2OIO; 20I2).

2 "Microbiome" refers to an "entire habitat, including the microorganisms (bacteria, archaea, lower and higher eukaryotes, and viruses), their genomes (i.e., genes), and the surrounding environmental conditions" (MARCHESI \& RAVEL 20I 5, 1), whereas "microbiota" refers to the collection of all the microorganisms (bacteria, fungi, viruses, etc.) that interact in a such environment. In this paper, the host is taken as the environment where those microorganisms interact (in this sense, there is no microbiota without a host where the microbiota grows and reproduces), and "microbiome" and "microbiota" will be used interchangeably. See Lederberg (2000) and Lederberg \& McCray (200I) for the first uses of the term.

${ }^{3}$ We cannot provide an exhaustive account of all the different dimensions of biological individuality in this paper. Those readers that are interested can check Clarke (2010), Pradeu (20I6A; 20I6B), DiFrisco (20I7), Lydgard \& Nyhart (2017). For our purposes in this paper, we will only concentrate on the evolutionary dimension of biological individuality. 
On the other hand, detractors of holobiont individuality claim that the current empirical evidence is not sufficient to claim that holobionts are functionally integrated entities and therefore, any claim about their status as biological individuals is ungrounded. It is important to highlight that detractors of holobionts individuality do not deny that some members of the microbiota might be sufficiently integrated with the host so as to constitute a unique biological individual (e.g. mitochondria in eukaryotes, Buchnera aphidicola in aphids, Wolbachia pipientis in some insects, etc.). What they deny is that a host plus all its symbiotic microbiota act together as a unique biological individual, and find more accurate to talk about independent individuals that live together in association (Booth 20I4; Moran \& SlOan 20I5; Godfrey-Smith 2015; Chiu \& Eberl 20i6; Douglas \& Werren 2016; HURST 20I7).

This debate concerning the status of holobionts (i.e. whether they are biological individuals or not) has been mainly approached from a conceptual and an epistemological framework that is proper of the philosophy of biology (see Treviño, unpublished manuscript). Yet, we consider that it has metaphysical consequences for our understanding of mereology, i.e. partwhole relations: which are the metaphysical grounds that move holobiont advocates to argue that they are individuals? How does part-whole relation work in the case of holobionts? This topic, notwithstanding, has never been approached from a purely metaphysical point of view. The purpose of this paper is to cover this gap by elaborating a metaphysical account of the holobiont as an emergent level of biological individuality. Drawing upon a conception of natural selection that only requires trait-recurrence among units of selection, we argue that holobionts exhibit metaphysically emergent properties that suggest their consideration as emergent individuals.

Our agenda will be as follows: in $\$ 1$ we provide an introduction to the philosophical concept of emergence, mainly inspired by Wilson's recent categorization of ontological emergence (2016). Later, in $\$ 2$, we present the trait-recurrence account of the units of selection, apply it to the holobiont, and explain what this account implies about the status of the holobiont as a biological individual. In $\$ 3$, we take a metaphysical step by arguing that the trait-recurrence conception of the holobiont entails that holobionts possess properties that allow them to downwardly affect the different entities that compose it (host and microbes of its microbiota). Finally, we conclude the paper by defending that the arguments presented in $\$ 1-\$ 3$ suggest that, from a metaphysical perspective, holobionts should be conceived as emergent individuals (\$4). 


\section{ONTOLOGICAL EMERGENCE: WEAK AND STRONG}

The idea of emergence was conceptually developed during the late 19th and the early 20th century due to the work of the British Emergentists (McLaughlin I992, I997; Kim 2006B). Until the second decade of the 20th century, emergentism was defended as a middle position between reductionism and vitalism. The British Emergentists defended that physical systems, when reaching a certain degree of complexity, can manifest new higher-level properties that are not possessed by the lower-level components of the system nor are reducible to them. Some properties considered as emergent were: life, mind, or chemical bonding.

Due to new explanations in physics accounting for some properties of chemical and biological systems so far considered to be irreducible, as well as the creation and awareness of complex non-linear systems (e.g. turbulent fluids), emergentism disappeared from the mainstream philosophy between the 1930s and 1970s (McLaughlin I992; Wilson 20I3). However, during the last decades of the 20th century, emergentism has reappeared in scientific and philosophical contexts due to the collapse of the reductionistic positions widely defended by the logical positivists (KIM 1989; I999; 2006в) and the widespread development of the so-called sciences of complexity (GoLDSTEIN i 999; Pepper \& Goldstein 2004; Witherington 20i I).

Current debates on emergence are oriented towards a conceptual clarification of the basic ideas associated with it, namely dependence and autonomy (Van Guilick 200i; Clayton 2006; Barnes 20i2). However, there is not a unified account of what emergence is yet (KIM 2006B; WILSON 20I6), which is problematic. It is not only that the variety of definitions is useless for clarifying the structure of natural reality (WILSON 20I6), but also that the philosophical characterizations of emergence are, in some cases, so complex and abstract that it seems really difficult to conceive of an emergent property in the world (McDonald \& McDonald 2009). However, in different scientific explanations, especially those regarding complex systems, the concept is widely used, and emergent properties are widely recognized. This fact seems to illustrate that there is an incompatibility between how the concept is defined by metaphysicians and how it is used and conceived by philosophers of science. In philosophy of biology, for instance, the abstract characterization of emergent properties in metaphysics is considered to be problematic, insofar as it is unable to make sense of the emergent character of some biological properties, such as the amount of nectar stored in a hive (MITCHELL 20 I2).

Due to the difficulties in providing an accurate definition of emergence that properly makes sense of its creed: dependence and autonomy, differ- 
ent criteria have been proposed to recognize emergent properties. For some authors, emergent properties are unpredictable, irreducible, and have causal powers (KIM 1999). Others have offered a more extensive list of criteria for a property to be emergent, namely holism, novelty, qualitative difference, not given at lower levels, different laws, and interaction (HuMPHREYs 1997). These criteria, as Paul Humphreys makes explicit (Humphreys 1997), are sufficient but not necessary to talk of emergence: they do not need to be met by all emergent properties, nor do all emergent properties need to share the same properties. This implies that different accounts of emergence might be given depending on the criteria one considers emergent properties need to meet (McDonald \& MCDonald 2009). Despite the extant definitions of emergence that are offered, it has been claimed that all of them can be grouped into a twofold categorization, namely weak ontological emergence and strong ontological emergence (WILSON 20I6). Ontological emergence refers to a kind of higher-level properties that are given in the world and that are characterized for being causally autonomous, in the sense that the causal power they possess cannot be reduced to the causal power of the lower-level properties of the system upon which they depend (КIM 2006B; JESPER 2006; McDonald \& McDonald 2009; Wilson 20i6). If the higher-level property of a system is not causally autonomous, then there is epiphenomenalism but not emergence.

The notion of causal power used to characterize emergent properties is, notwithstanding, a problematic one. It can be differently conceived depending on the ontological commitments one might have regarding properties. Here, we will follow Wilson's neutral account with respect to causal powers, according to which having a causal power means that the fact that the property is instantiated entails that the entity that bears it will have the power to, in appropriate circumstances, cause some effects, or intervene in the causation of some effects (WILsON 2002; 2016). Furthermore, when it is applied to emergent higher-level properties, it is considered that this causal power needs to be downwardly exerted (O'Connor I994, 97-8). Since the 1970s, downward causation is recognized as a central component of emergentism. In philosophy of biology, Donald Campbell suggested that the lower level entities of a system can behave in ways that they would not do, due to the constraints created by the higher level organization that they constitute (CAMPBELL I974). In this case, we also accept downward causation as one of the hallmarks of emergent properties, and thus, we will consider this feature when arguing for the presence of emergent properties in holobionts.

According to Wilson, the causal autonomous character of an emergent property might be given in two different forms, namely (1) because the 
higher-level property has a new causal power that is different from the causal powers of the lower-level properties of the system in which the property is instantiated (strong ontological emergence) ${ }^{4}$; and (2) because the higher-level property has a mere proper subset of the causal powers that the lower-level properties of the system in which it is instantiated have (weak ontological emergence). ${ }^{5}$ For strong ontological emergence, there is causal autonomy insofar as the emergent property incorporates new causal powers in the world. In cases of weak ontological emergence, conversely, the emergent property does not incorporate new causal powers. Yet, as Wilson claims, the weak emergent property still has a different and autonomous causal power profile since it only possesses a proper subset of the causal powers of the lower-level properties it depends on (WILsON 2016, 362). ${ }^{6}$

The characterization of emergence is generally attributed to properties. There are properties that emergent or not in a given system. However, in metaphysics, it is accepted that entities might be emergent in a derivational sense from the emergence of properties (BEDAU 2002; WILSON 2016). This is so since, in order for a property to be emergent, the system in which it is instantiated has to reach a certain degree of complexity, such that it is possible to characterize that system as an emergent one. In this regard, when a particular entity is characterized for having an emergent property, then it is considered to be an emergent entity as well. We accept this metaphysical claim, and thus, we consider that if holobionts possess emergent traits, then they are emergent entities.

\footnotetext{
${ }^{4}$ There is a wide debate in metaphysics concerning whether there are strong ontological emergent properties. An illustration of properties considered to be of this kind are consciousness (Chalmers 1996), fitness (Treviño, unpublished manuscript), and some properties of quantum mechanics (Silberstein \& McGeever i999).

${ }^{5}$ An example of weak ontological emergence can be offered in terms of the determinable/ determinate relation, such as the relation between colors and shades. Consider that train drivers are said to stop the train when the light of the traffic light is white. 'White' is a determinable that might be multiply determined by different determinates (i.e. the different shades of white) such as 'whitesmoke' or 'snow-white'. Regardless of whether the white of the traffic lights was determined by whitesmoke or snow-white, train drivers must stop the train if they saw the light. In this regard, the different determinates of white share the causal power of the determinable white: advising train drivers they must stop the train. However, they might also have more causal powers besides this one (snow-white might also have the causal power for polar bears to avoid predators, for instance), and they might differ precisely with regard to this other powers. The determinable white, therefore, only inherits a proper subset of the causal power of its determinates, which shows that its causal power profile is different from that of its determinates and that it is not reducible to them.

${ }^{6}$ The causal autonomy Wilson attributes to weak emergent properties on the basis of their different causal power profiles (see also WiLson I999; SHOEMAKER 2000) might be questionable. In fact, we do not agree with this way of conceiving causal autonomy since it seems to imply reduction. Yet, questioning this form of emergentism goes beyond the main task of this paper.
} 
In $\$ 3$, we will illustrate that holobionts possess some traits that are causally autonomous insofar as they attribute their bearers a new causal power that is not present in the lower-level properties of the parts that compose the holobiont, and that it is also downwardly exerted. Yet, before doing this, we will introduce the conceptual framework from which we conceive units of selection, and thus the role of holobionts as a unit of selection, and explain what this account implies about the status of the holobiont as a biological individual (\$2).

\section{TRAIT-RECURRENCE AS THE KIND OF STABILITY THAT MATTERS IN A HOLOBIONT}

One of the most problematic claims about the biological individuality of holobionts comes from the "hologenome concept of evolution" (HCE henceforth). HCE is the thesis that holobionts, with their hologenomes, are a unit of selection in evolution. ${ }^{7}$ For an individual to be a unit of selection it has to live in a population of individuals where: (a) different individuals exhibit different phenotypes; (b) different phenotypes are associated with different degrees of fitness; and (c) there is transgenerational inheritance, i.e. the offspring of those individuals that bear a trait $T$ will be more likely to bear $T$ than the offspring of those individuals that do not bear it. If holobionts are units of selection, as defenders of HCE claim, they have to demonstrate that holobionts satisfy properties (a)-(c).

Most of our current empirical evidence suggests that holobionts satisfy properties (a) and (b). However, the notion that holobionts are units of selection in evolution has been mainly challenged on the basis that there are no proper relations of inheritance across different holobiont generations, and therefore premise (c) is false (Moran \& SLOan 20 I 5 ; Douglas \& WerREN 20I6; HURST 2017). Their argument is grounded on the observation that the species that compose the microbiome of a holobiont do not remain intergenerationally constant, being replaced by different species across different generations of the host. Therefore, they argue, holobiont lineages are not coherent enough to be considered units of selection. Yet, this problem can be addressed if the question about species composition, as well as species transgenerational transmission, is substituted by the notion of transgenera-

\footnotetext{
${ }^{7}$ Not all the accounts that characterise holobionts as units of selection make a distinction between holobionts and hologenomes. Some authors claim that the holobiont is the interactor, and are mute with respect to the importance of hologenomes, whereas others simply deny the role of hologenomes as replicators. For a summary, see Sú́rez (20 I 8).
} 
tional trait-recurrence, which is the key element for discussions about the units of selection (SUÁREZ, unpublished manuscript). ${ }^{8}$

In such view of the units of selection, it becomes possible to understand the relations of inheritance across successive generations of holobionts throughout trait-recurrence. The main idea would be the following

A holobiont in generation $n+1$ will be a coherent unit of selection only if the traits $T_{1}, T_{2}, \ldots, T_{n}$, that appear in the holobiont $n+1$ are statistically correlated to the traits $T_{1}, T_{2}, \ldots, T_{n}$, that appeared in the holobiont $n .{ }^{9}$

This account of the units of selection can be characterized by four features. Firstly, the existence of transgenerational trait recurrence among holobionts is dependent upon host-generations (i.e. the host and its offspring are the units taken as referent to count generations of holobionts). As it is generally argued by most holobiont advocates, the life cycle of the holobiont is as long as the life cycle of the host (e.g. GILBERT 2018, 299), thus new generations of holobionts are recognized insofar as new generations of the host are recognized. Secondly, the criterion is theoretically formulated to recognize potential consistent relations of inheritance among holobionts. That is, to recognize possible parent-offspring relations among multispecies consortia ${ }^{10}$ that would support the claim that holobionts are units of selection (ZILBER-RosenberG \& Rosenberg 2008; Dupré \& O’Malley 2009; Rosenberg \& Zilber-RosenBerg 20I4, 20i6; Bordenstein \& Theis et 20i6; Theis et al. 20i6; Gilbert et al. 2017; Lloyd 2017B; Roughgarden et al. 2018). Thirdly, and contrary to other approaches to holobionts that conceive inheritance in terms of species transgenerational transmission (e.g. Moran \& SLOAN 2OI 5; Godfrey-SMith 2015; Stencel 20i6; Douglas \& Werren 20i6; Hurst 20i7; Stencel \&

\footnotetext{
${ }^{8}$ In agreement with most recent treatments of units of selection, we assume that an entity in a population is a unit of selection in evolution if it fulfils Lewontin's criteria, i.e. if the entity exhibits heritable phenotypic variance that affects its fitness (Lewontin I970; I985; OKASHA 2006; GodfreY-SMITH 2009). Contrary to other authors, we do not distinguish between the question of units of selection as interactors versus the question of units of selections as reproducers (e.g. LlOYD 20I7A).

${ }^{9}$ One reviewer has rightly pointed out that the model of trait recurrence is not exclusive for holobionts, but for every unit of selection. We agree with her that the account should work for every unit of selection. However, because in this paper we focus only on the case of the holobiont, we only restrict our comments to the consequence that the account would have for holobionts.

${ }^{10}$ Not all multispecies consortia are holobionts (e.g. biofilms, ecosystems), and our definition is formulated exclusively for holobionts, insofar as it assumes the existence of the host as the criterion that grants intergenerational identity, a circumstance that does not need to occur in all multispecies consortia.
} 
Whoch-SALAMON 20i 8), in this account, inheritance is reformulated in terms of reappearance of traits, i.e. reappearance of structures which, ceteris paribus, increase the fitness of the entities that bear them (Triviño \& NUÑo DE LA Rosa 20I6). Finally, the existence of non-species related trait-recurrence in holobionts (and thus, the validity of trait-recurrence as a conceptual criterion for defining holobionts as units of selection) is empirically supported by recent discoveries that suggest that some traits in macrobes appear as a consequence of their interaction with a functionally-equivalent microbiome, which, despite being taxonomically different for hosts of the same species, can still bring about the same metabolic traits through their interactions with the hosts (e.g. Burke et al. 20 I i; TaXis et al. 20 I 5; Hester et al. 2016; Louca et al. 20I6; LEMENCEAU et al. 2017).

According to the criterion of trait-recurrence, then, holobionts are biological individuals in virtue of their ability to reconstruct their traits transgenerationally by recruiting the members of their microbiota. One worry might arise at this point: why is the holobiont, and not the host, the entity that gets its traits reconstructed transgenerationally? The answer: because the recruitment of the members of the microbiota is not necessarily determined by the host, but co-determined by the interactions between the host and the microbiota (e.g. Gilbert \& Chiu 20 5; ChiU \& Eberl 20i6). There are three different channels to guarantee the acquisition of the microbiome: first, vertical transmission during conception (e.g. mitochondria in the eukaryotic cell; primary symbionts in many insects, including B. aphidicola in aphids) (BRIGHT \& BULGHERESI 20 IO); second, direct transmission during birth, or during weaning (FUNKHAUSER \& BordensteIN 20I3); and third, environmental acquisition, either through family/social interaction or through diet. The first two forms of acquisition do not put any pressure on the traditional definition of inheritance, as it is expected that they will happen by species-transmission. The third one, however, can only be conceptually understood by appealing to the notion of the units of selection just introduced, as in many cases of environmental acquisition of the microbiome there is no species constancy (i.e. the holobiont in generation $n+1$ does not environmentally acquire the same species of microbes that the holobiont in generation $n$ has acquired), despite the existence of transgenerational trait-recurrence.

Assuming: first, that those holobionts that acquire microorganisms that bring about fitter traits will (ceteris paribus) survive longer and reproduce more $^{11}$; and second, that there are mechanisms that guarantee the survival of

${ }^{11}$ That is to say, assuming that no other evolutionary factors (or forces) are putting pressure on the evolution of the population; i.e., assuming that natural selection is the only factor determining how the population evolves. 
the microorganisms outside the holobiont (e.g. BROwNE et al. 2017), as well as the existence of a higher degree of horizontal gene transfer among the members of a microbiome (e.g. LiU et al. 20 2 2; LeRner et al. 20I7). Then, there are three mechanisms that guarantee that environmental transmission of traits will be preserved across generations of holobionts in spite of the lack of the perfect vertical transmission of the species of the microbiome. These mechanisms are: (1) the genetics of the host, such that a host in generation $n+1$ will be more genetically predisposed to acquire functionally similar microorganisms than the host in generation $n$; (2) the immunological characteristics of the host, such that a host in generation $n+1$ will be more immunologically predisposed to acquire functionally similar microorganisms than the host in generation $n$; (3) the contact of the host with an environment where functionally similar microorganisms can easily survive and therefore tend to be present. These three mechanisms together increase the likelihood that a holobiont in generation $n+1$ will bear traits that are more similar to a holobiont in generation $n$ which is its progenitor, than to a random member of the population where it lives. This, therefore, suggests that holobionts can be conceived as biological individuals qua units of selection, in so far as the condition of inheritance is now satisfied by appealing to trait-recurrence.

\section{From trait-recurrence to downward causation}

In the previous sections ( $\$ 1$ and $\$ 2$ ) we introduced two separated nodes, the first one regarding the concept of emergence, and the second one about how to conceive holobionts, so that the notion that they are biological individuals qua units of selection makes sense. Here we connect the two nodes to argue that the conception of holobionts as generations of stabilized traits entails the metaphysical consequence that holobionts are emergent entities. In order to do so, we will illustrate that some of the traits that characterize holobionts have a new causal power that is downwardly manifested.

As we argued in $\$ 2$, transgenerational transmission among holobionts can be understood in terms of trait-recurrence: the likelihood that a trait $T$ that appears in a holobiont in generation $n$ will reappear in a holobiont in generation $n+1$ is higher than the likelihood that $T$ appears in a random member of the population $P$. Furthermore, as we argued, if $T$ increases the fitness of the holobiont, then ceteris paribus, it will be driven towards fixation in $P$. Because this can be so, then natural selection at the level of the holobiont is conceptually possible, as well as empirically verified in some cases (e.g. BRUCKER \& Bordenstein 20i 2; Mendoza et al. 20 i 8). An immediate consequence of the 
trait-recurrence model of holobiont selection is that the holobiont will exercise causal powers over the entities that compose it. In other words, because of the transgenerational trait-recurrence and selection at the level of the holobiont, the different entities that compose it will the action of natural be sorted. As a consequence, some of them will be eliminated from the environment, others will increase their frequency, and yet others will evolve so that they are able to fulfill the functions that cause the appearance of the traits that increase the fitness of the holobiont and, ceteris paribus, will tend to get fixed in $P$. This, we argue, is a form of downward causation at the level of the holobiont, since the holobiont determines which elements of the microbiome succeed transgenerationally and which do not, thus conditioning their evolutionary dynamics.

We can illustrate how trait-recurrence entails downward causation by means of an example. Let us take the case of the aphid holobiont (aphid + Buchnera aphidicola).$^{12}$ As it is well known, some elements of the holobiont's phenotype strongly depend on the interaction between the host and its microbiome. One standard trait that has been empirically studied is thermal tolerance, which is known to depend on the interaction between the host and the microbiome, therefore constituting a standard case of a holobiont trait (see Dunbar et al. 2007). The thermal tolerance of an organism dictates the range of temperatures where the organism can live and reproduce, therefore determining the types of environments where it is viable. As a trait, it confers certain selective advantages in those cases where the range of thermal tolerance is higher, as it means that the organism would be viable in a wider range of environments and thus, ceteris paribus, it will live longer and reproduce more. Importantly, hence, those aphid holobionts that have a higher degree of thermal tolerance will live longer and reproduce more than any other average aphid holobiont in the population. This will have two consequences: First, those aphids hosts whose holobiont has a higher degree of thermal tolerance will survive longer and reproduce more than an average member of the population; second, those B. aphidicola that are part of the microbiome with a higher degree of thermal tolerance will also survive longer and, more importantly, they will have more opportunity of spreading in the population of holobionts.

The second case, i.e. the spreading of B. aphidicola in the holobiont population, is a case of downward causation, where it is the holobiont the entity that causes $B$. aphidicola to spread in the population, therefore conditioning its evolutionary dynamics. To explain why, we need to start supposing that the

${ }^{12}$ We are conscious that the aphid holobiont would also include other elements of the aphid microbiome. Since our paper is not about philosophy of biology, but about metaphysics, we restrict our argument to the case of the aphid $+B$. aphidicola, which as our reviewer has correctly pointed out is not problematic for any of the contendants in the holobiont debate. 
holobiont population is only affected by the forces of natural selection, which would totally determine its evolutionary dynamics. We know that this situation is highly ideal and far from what happens in reality, where many evolutionary factors affect populations simultaneously, having sometimes opposing effects that cancel each other. However, this would not affect our metaphysical point: if we can demonstrate that, ceteris paribus, there is downward causation, then no matter what evolutionary factors would cancel their effects, there would be downward causation acting on B. aphidicola yet.

Now, supposing that some of the holobionts in the population will bear the trait that confers fitness advantages whereas others do not, the population can be divided into two groups: individuals that bear the trait $(A)$, and individuals that do not bear the trait $(B)$. It is known, by hypothesis, that the individuals of $A$ will survive longer and reproduce more than the individuals of $B$. If this is the case, then the $B$. aphidicola that compose the microbiome of the individuals in $A$ will also survive longer than the B. aphidicola of the individuals in $B$. Since it will survive longer, there will be more opportunity for spreading: the holobionts of $A$ will have more physical contact with other holobionts than those in $B$. Because this is so, it is more likely that their $B$. aphidicola will get passed, in the scenario where it is acquired by horizontal transmission: more contacts means more opportunity for getting passed, and more opportunity for getting passed means more likelihood of getting fixed in the population. ${ }^{13}$ This is so because of the opportunity of longer contact with those holobionts in $A$ (by hypothesis they live longer) and the different opportunities that microorganisms have to survive in the environment.

On the other hand, in the case that the B. aphidicola are transmitted vertically, it will also be the case that they will increase their numbers in the population necessarily, as those holobionts that bear the trait that confer fitness advantages will, by hypothesis, reproduce more than those that do not. If this is is so, then we would have a case where the selection of these holobionts that bear the trait that confers the fitness advantages determines that those microorganisms that constitute their microbiome are sorted differentially. The causation, thus, works from the higher-level entity to its lower level parts, therefore constituting an example of downward causation.

Two metaphysical consequences about the ontological status of holobionts can be deduced from the previous example. Firstly, we argue that the form of dependence that exists between the traits in a holobiont and the lower-level

${ }^{13}$ The case developed here is supposed to cover every possible hypothetical scenario. It is known that $B$. aphidicola is only transmitted vertically in aphids. But many of the members of the microbiome in different species are transmitted horizontally. And this is the only thing that matters for our conceptual purposes here. 
parts that determine the appearance of those traits is a form of strong ontological emergentism (WiLson 20I6). This is so for two reasons: first, because those traits appear and are maintained as a consequence of the interaction between the host and the microbiome; in other words, the host without the microbiome or the microbiome without the host do not cause those traits to appear, which suggests that they are specific to the holobiont and therefore non reducible to the host (irreducibility of the traits); and second, because those traits are usually multiply-realizable; that is, those traits appear as a consequence of the interaction between the host and a microbiome, but the components of the microbiome that cause those traits to appear might differ among different hosts of the same species, while the same traits still appear (multiple realizability of the traits). Secondly, we argue that the existence of downward causation, insofar as it implies strong ontological emergentism (WILSON 20I6), entails the possibility of conceiving holobionts as emergent individuals in virtue of having emergent traits. In this sense, holobionts would be a new level of biological individuality, with their own properties (traits) that have causal consequences on the parts that constitute them and, therefore, a genuine new level in the biological hierarchy.

\section{Concluding Remarks: Holobionts as emergent individuals}

This paper argued that holobionts can ontologically be conceived as emergent individuals on the basis that they possess properties that allow them to exercise downward causation on the entities that compose them. Drawing upon the trait-recurrence model of holobiont individuality, we argued that a consequence of holobionts selection was the sorting of the entities that constitute the holobiont. In other words, we argued that the holobiont, as a unit of selection, exercises downward causation over the entities that constitute it, causing its differential degrees of evolutionarily success or failure. We further argued that the existence of this downward causation was compatible with strong emergentism and, therefore, with the hypothesis that holobionts are emergent ontological individuals.

\section{Acknowledgments}

We would like to acknowledge Laura Nuño de la Rosa, and Cristina Villegas for inviting us to participate in this special issue, as well as for their careful reading of the first version of the paper. We also want to extend this acknowledgment to our anonymous referee, who had the patience to give us a really valuable feedback that helped us to improve our initial draft. Javier 
Suárez would like to formally acknowledge the Spanish Ministry of Education (FFU16/02570) and the Spanish Ministry of Economy and Competitiveness (FFI2016-76799-P) for their economic support. Vanessa Triviño would also like to thank the "Fundación Séneca. Agencia de Ciencia y Tecnología de la Región de Murcia" (19489/PI/14), and the Spanish Ministry of Economy and Competitiveness (FFI2017-87193-P). 


\section{REFERENCES}

BARnES, E. 20I2, "Emergence and Fundamentality", Mind, 121: 873-901.

Bоотн, A. 20 I4, "Symbiosis, selection and individuality", Biology and Philosophy, 29: 657-73.

Bordenstein, S. \& Theis, K. 20i6, "Host biology in the light of the microbiome: Ten principles of holobionts and hologenomes". PLOSBiology.DOI:10.1371/ journal.pbio.1002226.

Burke, C.; Steinberg, P.; Rusch, D.; Kjellberg, S. \& Thomas, T. 20 i i, "Bacterial community assembly based on functional genes rather than species. Proceedings of the National Academy of Sciences, 108 (34):14288-93.

Campbell, D. T. 1974, "Downward causation in hierarchically organized biological systems", Ayala, F. J. \& Dobzhansky, T. (ed.), Studies in the Philosophy of Biology, Berkeley/Los Angeles: University of California Press, 179-86.

Chalmers, D. 1996, The Conscious Mind: In Search of a Fundamental Theory, Oxford: Oxford University Press.

Chiu, L. \& Eberl, G. 20 i 6, "Microorganisms as scaffolds of biological individuality: An eco-immunity account of the holobiont", Biology and Philosophy, 31: 819-37.

Clarke, E. 20io, "The problem of biological individuality", Biological Theory, 5 (4): 312-25.

Clayton, P. 2006, "Conceptual Foundations of Emergence Theory", The ReEmergence of Emergence, Oxford: Oxford University Press.

DíAz, J. S. 20 I 5 , "El mecanismo evolutivo de Margulis y los niveles de selección”, Contrastes. Revista Internacional de Filosofía, XX (1): 7-24.

DiFrisco, J. 2017, "Kinds of biological individuals: Sortals, projectability, and selection", The British Journal for the Philosophy of Science.

Doolittle, W. F. \& Bоотн, A. 20I7, "It's the song not the singer: an exploration of holobiosis and evolutionary theory", Biology and Philosophy, 32: 5-24.

Douglas, A. \& Werren, J. 20i6, "Holes in the hologenome: why host-microbe symbioses are not holobionts", mBio, 7 (2): e02099-15.

Dupré, J. 2010, “The polygenomic organism”, The Sociological Review, 58 (s1): 19-30.

Dupré, J. 20 I 2, Processes of Life: Essays in the Philosophy of Biology, Oxford: Oxford University Press.

Funkhouser, L. J. \& Bordenstein, S. R. 20i 3, "Mom Knows Best: The Universality of Maternal Microbial Transmission”, PLoS Biology 11 (8): e1001631.

Gilbert, S.; Sapp, J. \& Tauber, A. 20 i 2, "A symbiotic view of life: We have never been Individuals", The Quarterly Review of Biology, 87 (4): 325-41. 
Gilbert, S.; Rosenberg, E. \& Zilber-Rosenberg, I. 2017, “The holobiont with its hologenome is a level of selection in evolution”, Gissis S.; LAMM, E. \& Shavit, A. (ed.), Landscapes of collectivity in the life sciences, London: The MIT Press, 305-24.

Goldstein, J. I999, "Emergence as a Construct: History and Issues", Emergence, 1: 49-72.

Hester, E.; Barott, K.; Nulton, J.; Vermeij, M. \& Rohwer, F. 20i 6, "Stable and sporadic symbiotic communities of coral and algal holobionts", The ISME Journal, 10: 1157-69.

Humphreys, P. 1997, "How Properties Emerge”, Philosophy of Science, 64: 1-17.

Hurst, G. 20I7, "Extended genomes: symbiosis and evolution”, Interface Focus, 7: 20170001.

Jesper, K. 2006, “The causal exclusion argument”, Philosophical Studies: An International Journal for Philosophy in the Analytic Tradition, 131 (2): 458-85.

KIM, J. I 989, "The Myth of Non-reductive Materialism", Proceedings and Addresses of the American Philosophical Association, 63 (3): 31-47.

KIM, J. I999, "Making sense of Emergence”, Philosophical Studies, 95: 3-36.

KIM J. 2006в, "Emergence: Core ideas and Issues", Synthese, 151: 547-59.

Lemanceau, P.; Blouin, M.; Muller, D. \& Moënne-Loccoz, Y. 2017, "Let the core microbiota be functional, TRENDS in Plant Science, 22 (7): 583-95.

Lloyd, E. 20I7A, "Units of selection”, E. N. Zalta (ed.), The Stanford Encyclopaedia of Philosophy. https://plato.stanford.edu/entries/selection-units/

LLOYD, E. 20I7B, "Holobionts as units of selection: Holobionts as interactors, reproducers, \& manifestors of adaptation”, Gissis, S.; Lamm, E. Shavit, A. (ed.), Landscapes of collectivity in the life sciences, London: MIT Press, 351-67.

Louca, S.; Jacques, S.; Pires, A.; Leal, J.; Srivastava, D.; Parfrey, L.; Farjalla, V. \& Michael, D. 20I6, "High taxonomic variability despite stable functional structure across microbial communities", Nature Ecology and Evolution, 1: 15.

Macdonald, C. \& Macdonald, G. 2009, Emergence and Downward Causation.

McLaughlin, B. I992, "The Rise and Fall of British Emergentism”, Beckerman, A.; Flohr, H. \& Kim, J. (ed.), Emergence or Reduction? Essays on the Prospects of Non-Reductive Physicalism, Berlin: De Gruyter, 49-93.

McLaughlin, B. I997, "Emergence and Supervenience", Intellectica, 2: 25, 25 43.

Mitchell, S. 2012, "Emergence: Logical, Functional and Dynamical", Synthese, 185 (2): 171-86.

Moran, N. \& SlOan, D. 20 I 5 , “The Hologenome Concept: Helpful or Hollow?”, PLoSBiol, 13 (12): e1002311.

O’Connor, T. I994, "Emergent Properties”, American Philosophical Quarterly, 31: 91-104. 
O’Malley, M. \& Dupré, J. 2007, “Size doesn't matter: Towards a more inclusive philosophy of biology", Biology and Philosophy, 22: 155-91.

Pepper, S. \& Goldstein, J. 2004, Emergence: Complexity and Organization. DOI: 10.emerg/10.17357.8163f5b43a8f4de73879e679bb0a5b95

Pradeu, T. 20i6A, "The many faces of biological individuality", Biology and Philosophy, 31: 761-73.

Pradeu, T. 2016B, "Organisms or biological individuals? Combining physiological and evolutionary individuality", Biology and Philosophy, 31: 797-817.

Rosenberg, E.; Koren, O.; Reshef, L.; Efrony, R. \& Zilber-Rosenberg, I. 2007, "The role of microorganisms in coral health, disease and evolution", Nature Reviews: Microbiology, 5: 355-62.

Rosenberg, E. \& Zilber-Rosenberg, I. 20 i 4, The Hologenome Concept, London: Springer.

Rosenberg, E. \& Zilber-Rosenberg, I. 20i6, "Microbes drive evolution of animals and plants: the hologenome concept", mBio, 7 (2): e01395-15.

Roughgarden, J.; Gilbert, S.; Rosenberg, E.; Zilber-Rosenberg, I. \& Lloyd, E. 2017, "Holobionts as Units of Selection and a Model of their Population Dynamics and Evolution”, Biological Theory, 13: 44-65.

Shoemaker, S. 2000, "Realization and Mental Causation", Proceedings of World Congress in Philosophy, Cambridge: Philosophy Documentation Center.

Shropshire, J. \& Bordenstein, S. 20i6, "Speciation by symbiosis: the microbiome and behavior", mBio, 7 (2): e01785-15.

Silberstein, M. \& McGeever, J. I999, "The search for ontological emergence", The Philosophical Quarterly, 48: 125, 182-200.

Skillings, D. 2016, "Holobionts and the ecology of organisms: Multi-species communities or integrated individuals?", Biology and Philosophy, 31: 875-92.

Stencel, A. 2016, "The relativity of Darwinian populations and the ecology of endosymbiosis", Biology and Philosophy 31 (5): 619-37.

Stencel, A. \& Wloch-Salamon, D. M. 20i 8, "Some theoretical insights into the hologenome theory of evolution and the role of microbes in speciation", Theory in Biosciences, 137 (2): 197-206.

SuÁrez, J. 201 8, “The importance of symbiosis in philosophy of biology: An analysis of the current debate in biological individuality and its historical roots", Symbiosis, 76 (2): 77-96.

SuÁrez, J. (unpublished manuscript), "Stability of traits as the kind of stability that matters. Holobionts as units of selection from a multilevel selection framework".

Taxis, T.; Wolff, S.; Gregg, S.; Minton, N.; Zhang, C.; Dai, J.; Schnabel, R.; Taylor, J.; Kerley, M.; Pires, J.; Lamberson, W. \& Conant, G. 20 i 5 , “The 
players may change but the game remains: network analyses of ruminal microbiomes suggest taxonomic differences mask functional similarity", Nucleic Acids Research, 43 (20): 9600-12.

Theis, K.; Dheilly, N.; Klassen, J.; Brucker, R.; Baines, J.; Bosch, T.; Cryan, J.; Gilbert, S.; Goodnight, C.; Lloyd, E.; Sapp, J.; Vandenkoornhuyse, P.; Zilber-Rosenberg, I.; Rosenberg, E. \& Bordenstein, S. 20i 6, "Getting the hologenome concept right: an eco- evolutionary framework for hosts and their microbiomes", mSystems, 1 (2): e00028-16.

Triviño, V. (unpublished manuscript). "A study of the interactions between metaphysics and biology: towards a metaphysics of biology."

Triviño, V. \& Nuños de la Rosa, L. 20i6, "A Causal Dispositional Account of Fitness", History and Philosophy of the Life Sciences, 38 (3): 1-18.

VAN Gulick, R. 200I, "Reduction, Emergence and other Recent Options on the Mind/Body Problem: a Philosophical Overview", Journal of Consciousness Studies, 8: 9-10, 1-34.

Wilson, J. I999, "How Superduper does a Physicalists Supervenience Need to be?", The Philosophical Quarterly, 49: 33-52.

Wilson, J. 2002, "Causal Powers, Forces and Superdupervenience, Grazer Philosophische Studien, 63: 53-78.

Wilson, J. 20I3, "Nonlinearity and Metaphysical Emergence", S. Mumford \& M. Tugby (ed.), Metaphysics and Science, Oxford: Oxford University Press, 201-35.

Wilson, J. 20I6, "Metaphysical emergence: weak and strong", T. BigaJ \& C. Wüthrich (ed.), Metaphysics in Contemporary Physics, Boston: Brill Rodopy, 345-402.

Witherington, D. 20 i I, "Taking Emergence Seriously: The Centrality of Circular Causality for Dynamic Systems Approaches to Development", Human Development, 54: 66-92.

Zilber-Rosenberg, I. \& Rosenberg, E. 2008, "Role of microorganisms in the evolution of animals and plants: the hologenome theory of evolution", FEMS Microbiol Rev: 723-73. 